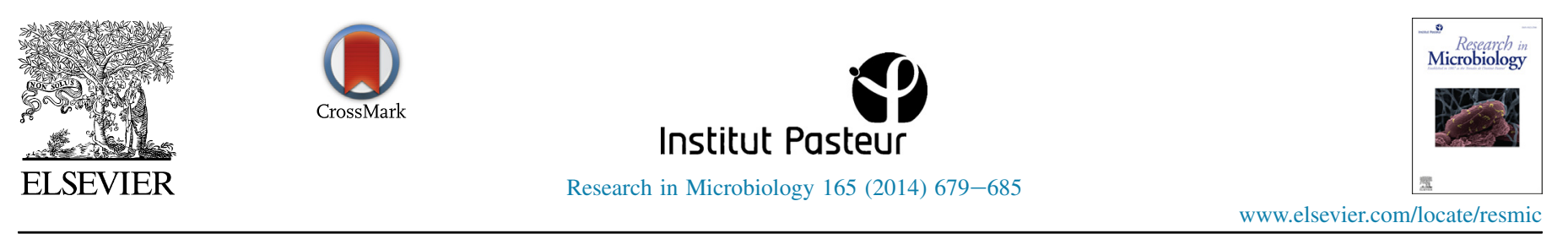

Original article

\title{
Characterization of Staphylococcus epidermidis phage vB_SepS_SEP9 - a unique member of the Siphoviridae family
}

\author{
Luís D.R. Melo ${ }^{\text {a }}$, Sanna Sillankorva ${ }^{\text {a }}$, Hans-Wolfgang Ackermann ${ }^{\text {b }}$, Andrew M. Kropinski ${ }^{\text {c,d }}$, \\ Joana Azeredo ${ }^{a}$, Nuno Cerca ${ }^{a}, *$ \\ ${ }^{\text {a } C E B}$ - Centre of Biological Engineering, LIBRO - Laboratory of Research in Biofilms Rosário Oliveira, University of Minho, Campus de Gualtar, \\ 4710-057 Braga, Portugal \\ ${ }^{\mathrm{b}}$ Department of Microbiology, Immunology and Infectiology, Faculty of Medicine, Laval University, Québec, QC G1X 4C6, Canada \\ ${ }^{\mathrm{c}}$ Public Health Agency of Canada, Laboratory for Foodborne Zoonoses, Guelph, ON N1G 3W4, Canada \\ ${ }^{\mathrm{d}}$ Department of Molecular and Cellular Biology, University of Guelph, ON N1G 2W1, Canada
}

Received 2 April 2014; accepted 29 September 2014

Available online 7 October 2014

\begin{abstract}
Relatively few phages $(<10)$ of coagulase negative staphylococci (CoNS) have been described. Staphylococcus epidermidis phage vB_SepS_SEP9 is a siphovirus with a unique morphology as a staphylococcal phage, possessing a very long tail. Its genome is unique and unrelated to any phage genomes deposited in public databases. It appears to encode a nonfunctional integrase. Due to the not having a recognizable lysogeny module, the phage is unable lysogenize. The genome comprises 129 coding sequences (CDS), 46 of which have an assigned function and 59 are unique. Its unique morphology and genome led to the proposal of the establishment of a new Siphoviridae genus named "Sep9likevirus".
\end{abstract}

(c) 2014 Institut Pasteur. Published by Elsevier Masson SAS. All rights reserved.

Keywords: Staphylococcus epidermidis; Bacteriophages; Siphoviridae; Genomics

\section{Introduction}

Many Staphylococcus species are associated with nosocomial infections, endocarditis, sepsis, pneumonia and other diseases, being now considered a threat to public health $[1,2]$. The interest in Staphylococcus phages has increased significantly mostly due to the increasing resistance of this bacterium to antibiotics [3].

Phages can be characterized by many taxonomical criteria, while the nomenclature of phage taxa is regulated by the International Committee on the Taxonomy of Viruses (ICTV) [4]. Staphylococcal phages have been classified into distinct groups, or clusters, based on virion characteristics (dimensions, particle

\footnotetext{
* Corresponding author.

E-mail address: nunocerca@ceb.uminho.pt (N. Cerca).
}

weight, buoyant density) and DNA (molecular weight, $\mathrm{G}+\mathrm{C}$ $\%$, genome sequences) [5-8].

The reduction in sequencing costs has caused an increasing number of phage genomes to be deposited in online databases, presently over 1400 (http://www.ebi.ac.uk/genomes/phage. html). Over 80 of these genomes are of staphylococcal phages, $90 \%$ of which are viruses infecting Staphylococcus aureus. Recently, 46 fully sequenced Siphoviridae genomes of staphylococcal phages were analyzed, according to nucleotide and protein sequences and phage morphology. This analysis resulted in the proposal of the genera "3alikeviruses," "77likeviruses" and "Phietalikeviruses" [9]. In addition to siphoviral staphylococcal phages, there are four sequenced phages of the Podoviridae family, all of which belong to the 44AHJD-like genus of the Picovirinae subfamily, and while the majority of the 13 sequenced Myoviridae phages, belong to the Twortlikevirus genus of the Spounaviridae subfamily there 
are a few that still remain unclassified (http://www.ebi.ac.uk/ genomes/phage.html).

To date, only a few genomes from phages for coagulase negative staphylococci (CoNS) of the following species have been sequenced and characterized: six for Staphylococcus epidermidis [10-13], two for Staphylococcus hominis [5] and one for Staphylococcus capitis [5]. Of these CoNS phage genomes, one $S$. epidermidis phage is from the Myoviridae family [13], while all others belong to the Siphoviridae family.

The current interest in finding new S. epidermidis phages is due to the implication of this organism as the second major cause of bloodstream infections [14]. Previously, we isolated five different $S$. epidermidis phages and fully characterized one of them, the broad-host-range Twortlikevirus phage SEP1 [13]. Phage vB_SepS_SEP9 (SEP9) also has a broad lytic spectrum but produces completely different plaques. This prompted the investigation of its morphology and genome, which showed unique features.

\section{Materials and methods}

\subsection{Bacterial strains and growth conditions}

Forty-six staphylococcal strains belonging to four different species were used in this study, namely 38 clinical isolates of S. epidermidis and two Staphylococcus haemolyticus, four $S$. aureus collection strains and three Staphylococcus intermedius veterinary isolates (Table 1). All strains were grown in Tryptic Soy Broth (TSB, Oxoid), on Tryptic Soy Agar (TSA, Oxoid) or in TSA soft agar overlays $(0.4 \%$ agar $)$ at $37^{\circ} \mathrm{C}$.

\subsection{Phage propagation}

Phage SEP9 was isolated from raw effluents of a wastewater treatment plant (ETAR de Frossos, Braga, Portugal) [13]. Phage particles were amplified in solid media as described elsewhere [13], using the double agar layer method with S. epidermidis M129 as the host. Phages were spread on the host bacterial lawns using paper strips. After overnight incubation at $37{ }^{\circ} \mathrm{C}$ and observation of lysis, $4 \mathrm{ml} \mathrm{SM}$ buffer (100 mM NaCl, $8 \mathrm{mM} \mathrm{MgSO}$, $50 \mathrm{mM}$ Tris/HCl (pH 7.5), $0.002 \%(\mathrm{w} / \mathrm{v})$ gelatin were added to each plate. After $24 \mathrm{~h}$ agitation at 120 RPM (PSU-10i Orbital Shaker (BIOSAN, Riga, Latvia)) at $4{ }^{\circ} \mathrm{C}$, the homogenized top-agar layer was collected, centrifuged $\left(10 \mathrm{~min}, 10,000 \times \mathrm{g}, 4^{\circ} \mathrm{C}\right)$ and filtered as described before. Chloroform $(10 \mathrm{ml})$ was added to each $50 \mathrm{ml}$ of phage suspension and samples were stored at $4{ }^{\circ} \mathrm{C}$.

SEP9 was titrated essentially as described elsewhere [15]. Samples were serially diluted in SM buffer, after that $100 \mu$ of each phage dilution and $100 \mu \mathrm{l}$ of host bacterium were mixed with $3 \mathrm{ml}$ of a soft agar top-layer. PFU (plaque forming unit) were counted after $18 \mathrm{~h}$ incubation at $37^{\circ} \mathrm{C}$.

\subsection{Electron microscopy}

Transmission electron microscopy was performed as described by Melo et al. [13]. Briefly, phage particles were
Table 1

SEP9 host range and EOP on different staphylococci.

\begin{tabular}{|c|c|c|}
\hline Strain & Infectivity & $\mathrm{EOP}^{\mathrm{a}}$ \\
\hline S. epidermidis M129 & + & High \\
\hline S. epidermidis DEN110 & + & High \\
\hline S. epidermidis FJ6 & + & High \\
\hline S. epidermidis ICE21 & + & High \\
\hline S. epidermidis ICE9 & + & High \\
\hline S. epidermidis IE186 & + & High \\
\hline S. epidermidis IE75 & + & High \\
\hline S. epidermidis ITL34 & + & High \\
\hline S. epidermidis JI6 & + & High \\
\hline S. epidermidis URU23 & + & High \\
\hline S. epidermidis 9142 & + & Moderat \\
\hline S. epidermidis DEN19 & + & Moderat \\
\hline S. epidermidis TAW113 & + & Low \\
\hline S. epidermidis 1457 & + & LFW \\
\hline S. epidermidis $\mathrm{COB} 20$ & + & LFW \\
\hline S. epidermidis DEN116 & + & LFW \\
\hline S. epidermidis DEN120 & + & LFW \\
\hline S. epidermidis DEN185 & + & LFW \\
\hline S. epidermidis GRE26 & + & LFW \\
\hline S. epidermidis ICE120 & + & LFW \\
\hline S. epidermidis ICE192 & + & LFW \\
\hline S. epidermidis ICE24 & + & LFW \\
\hline S. epidermidis LE7 & + & LFW \\
\hline S. epidermidis $\mathrm{MCO} 150$ & + & LFW \\
\hline S. epidermidis MEX37 & + & LFW \\
\hline S. epidermidis PE9 & + & LFW \\
\hline S. epidermidis PLN64 & + & LFW \\
\hline S. epidermidis RP62A & + & LFW \\
\hline$S$ epidermidis CV45 & - & - \\
\hline S. epidermidis COB 17 & - & - \\
\hline S. epidermidis DEN69 & - & - \\
\hline S. epidermidis DEN94 & - & - \\
\hline S. epidermidis HUR51 & - & - \\
\hline S. epidermidis ICE102 & - & - \\
\hline S. epidermidis ICE21 & - & - \\
\hline S. epidermidis ICE5 & - & - \\
\hline S. epidermidis IE214 & - & - \\
\hline S. epidermidis MEX60 & - & - \\
\hline S. intermedius 4363 & - & - \\
\hline S. intermedius 4837 & - & - \\
\hline S. intermedius 4878 & - & - \\
\hline S. haemolyticus IE246 & - & - \\
\hline S. haemolyticus M176 & - & - \\
\hline S. aureus CECT 86 & - & - \\
\hline S. aureus CECT 239 & - & - \\
\hline S. aureus CECT 976 & - & - \\
\hline
\end{tabular}

${ }^{a}$ The EOP was recorded as high, moderate, low and lysis from without (LFW) representing $10,0.1-1,0.1 \%$, and no individual plaques formed, respectively.

collected after centrifugation $\left(1 \mathrm{~h}, 25000 \times \mathrm{g}, 4{ }^{\circ} \mathrm{C}\right)($ Beckman J2-21 centrifuge with a JA-18.1 rotor). Using the same conditions the pellet was washed twice in tap water. Phages were deposited on copper grids with carbon-coated Formvar films, stained with $2 \%$ uranyl acetate $(\mathrm{pH} 4.0)$ and observed using a Philips EM 300 electron microscope [16]. Magnification was monitored with $\mathrm{T} 4$ phage tails.

\subsection{Host range and efficiency of plating (EOP)}

Host range and EOP of phage SEP9 were determined by dropping $5 \mu \mathrm{l}$ aliquots from a 10 -fold dilution series of the 
phage, starting at $10^{9} \mathrm{PFU} \mathrm{ml} l^{-1}$, on double-layer agar plates seeded with the 47 staphylococcal strains to be tested. Plaques were counted after $24 \mathrm{~h}$ of incubation at $37^{\circ} \mathrm{C}$. The EOP was calculated by comparing the numbers of PFU on phagesusceptible strains to PFU obtained with S. epidermidis M129.

\subsection{One-step growth curve}

One-step growth analysis of SEP9 was performed as described previously [13]. Briefly, a mid-exponential phase culture at an $\mathrm{OD}_{600}$ of 0.5 was centrifuged $(5 \mathrm{~min}, 7000 \times \mathrm{g}$, $4{ }^{\circ} \mathrm{C}$ ) and resuspended in $10 \mathrm{ml}$ of fresh TSB to attain an $\mathrm{OD}_{600}$ of 1.0. SEP9 was added to this suspension to a MOI of 0.005 . After incubation for $5 \mathrm{~min}$ at $37^{\circ} \mathrm{C}$ and $120 \mathrm{RPM}$ to allow for adsorption, the culture was centrifuged and the pellet resuspended in fresh warm TSB. Samples were taken every $5 \mathrm{~min}$ over a period of $30 \mathrm{~min}$ and then every $10 \mathrm{~min}$ until $1 \mathrm{~h}$ post-infection and titrated.

\subsection{Nature of the phage}

To determine whether SEP9 is virulent or temperate, putative lysogens were isolated as described elsewhere with some modifications [17]. Briefly, the host strain was grown in broth overnight being further diluted 1/1,000,000 fold into 20 tubes of broth and regrown to late log phase. Phage was added to an MOI of 10 to the culture, allowed to attach for $15 \mathrm{~min}$ and plated out. One colony was selected per plate, streaked out 3 times and then tested for: (a) insensitivity for superinfecting phage, (b) spontaneous production of phage, and (c) PCR.

A primer pair was designed to amplify $537 \mathrm{bp}$ of the major capsid protein of SEP9 (SEP9-mcp). Amplification products were generated by PCR, using KAPA Taq PCR Kit (Kapa Biosystems, Boston, MA, USA). The reaction was performed in $25 \mu \mathrm{l}$, containing $1 \times$ KAPA Taq Buffer, containing a final concentration of $1.5 \mathrm{mM} \mathrm{MgCl}_{2}, 0.2 \mathrm{mM}$ of each dNTP, $0.4 \mu \mathrm{M}$ of each primer (SEP9-mcp-F $5^{\prime}-$ AAGCAGGTTTCGTTGGAGAA $3^{\prime}$; SEP9-mcp-R5' - CACCAATGTTGCCAAAGATG $3^{\prime}$ ), IU KAPA Taq DNA Polymerase and $25 \mathrm{ng}$ of DNA template using the following steps: denaturation at $95{ }^{\circ} \mathrm{C}$ for 3 min followed by 35 cycles of denaturation at $95{ }^{\circ} \mathrm{C}$ for $30 \mathrm{~s}$; annealing at $50{ }^{\circ} \mathrm{C}$ for $30 \mathrm{~s}$ and elongation at $72{ }^{\circ} \mathrm{C}$ for $45 \mathrm{~s}$, ending with an additional elongation step of $10 \mathrm{~min}$ at $72{ }^{\circ} \mathrm{C}$. The amplified products were analyzed by electrophoresis on a $1.5 \%$ agarose gel.

\subsection{Genome sequencing and analysis}

SEP9 total DNA was extracted as described before [13]. Briefly, before DNA extraction, the concentrated crude lysate was treated with $0.016 \%(\mathrm{v} / \mathrm{v}) \mathrm{L} 1$ buffer $[300 \mathrm{mM} \mathrm{NaCl}$, $100 \mathrm{mM}$ Tris/ $\mathrm{HCl}$ (pH 7.5), $10 \mathrm{mM}$ EDTA, $0.2 \mathrm{mg} \mathrm{BSA} \mathrm{ml}^{-1}$, $20 \mathrm{mg}$ RNase A ml${ }^{-1}$ (Sigma), $6 \mathrm{mg}$ DNase $\mathrm{I} \mathrm{ml}^{-1}$ (Sigma)] for $2 \mathrm{~h}$ at $37^{\circ} \mathrm{C}$. After a thermal inactivation of the enzymes for $15 \mathrm{~min}$ at $70{ }^{\circ} \mathrm{C}, 50 \mu \mathrm{g}$ proteinase $\mathrm{K} \mathrm{ml}^{-1}, 20 \mathrm{mM}$ EDTA and $1 \%$ SDS were added and proteins were digested for $18 \mathrm{~h}$ at
$56{ }^{\circ} \mathrm{C}$. SEP9 was extracted with one volume phenol:chloroform:isoamyl alcohol solution (25:24:1, v/v). After repeating the previous step, an equal volume of chloroform was added. The supernatant was precipitated on ice with isopropanol $3 \mathrm{M}$ sodium acetate ( $\mathrm{pH} 4.6)$, air-dried and it was resuspended in nuclease-free water (Cleaver Scientific, Rugby, UK). Genome sequencing was performed on a 454 sequencing platform (Plate-forme d'Analyses Génomiques at Laval University, Québec, Canada) to 50-fold coverage. Sequence data was assembled using SeqMan NGen4 software (DNASTAR, Madison, WI, USA).

The genome of this virus was autoannotated, using MyRAST [18]. The presence of non-annotated CDSs, along with genes in which the initiation codon was miscalled, were checked manually using Geneious 6.1.6 (Biomatters, San Francisco, CA, USA). BLASTX was used to examine for potential frameshifts [19] and BLASTP were used to search for homologous proteins [20], with an $E$ value threshold of $<1 \times 10^{-5}$. Protein motif search was HHpred using Pfam, InterProScan, and COG with an $E$ value threshold of $<1 \times 10^{-5}$ and at least $80 \%$ query coverage [21]. The presence of transmembrane domains was checked using TMHMM [22] and Phobius [23] and were annotated when both tools were in concordance. Protein molecular weight $(\mathrm{Mw})$ and isoelectric point $(\mathrm{pI})$ were determined using ExPASy Compute $\mathrm{pI} / \mathrm{Mw}$ [24]. The search of putative tRNA encoding genes was done using ARAGORN [25] and tRNAscan-SE [26]. Fragments 100 bp upstream of each predicted ORF were extracted and MEME [27] was used to search for putative promoter regions that were further manually verified. Rho-independent terminators were predicted using ARNold [28] and the energy was calculated using Mfold [29].

\subsection{Nucleotide sequence accession number}

The genome sequence of Staphylococcus phage vB_SepS_SEP9 was deposited in the GenBank database under the accession number KF929199.

\section{Results and discussion}

\subsection{SEP9 isolation and morphology}

S. epidermidis phage SEP9 was isolated previously [13] and is herein characterized. On $0.4 \%$ agar plates, SEP9 formed $0.9 \mathrm{~mm}$ clear plaques surrounded by an increasingly turbid halo indicative of the presence of depolymerase activity [30]. This phage was designated vB_SepS_SEP9, in accordance with the recommendations proposed by Kropinski et al. [31]. Electron microscopy showed a siphovirus with a head of $64 \mathrm{~nm}$ in diameter and a very long flexible tail of $375 \times 10 \mathrm{~nm}$, conspicuous transverse striations and a six-sided star-like baseplate (Fig. 1). Heads were icosahedra, as shown by the observation of both hexagonal and pentagonal capsids. In addition to normal heads, we observed occasional small heads of about $55 \mathrm{~nm}$ in diameter. A similar phenomenon was also reported for coliphage $\mathrm{P} 1$, which produces heads of three 


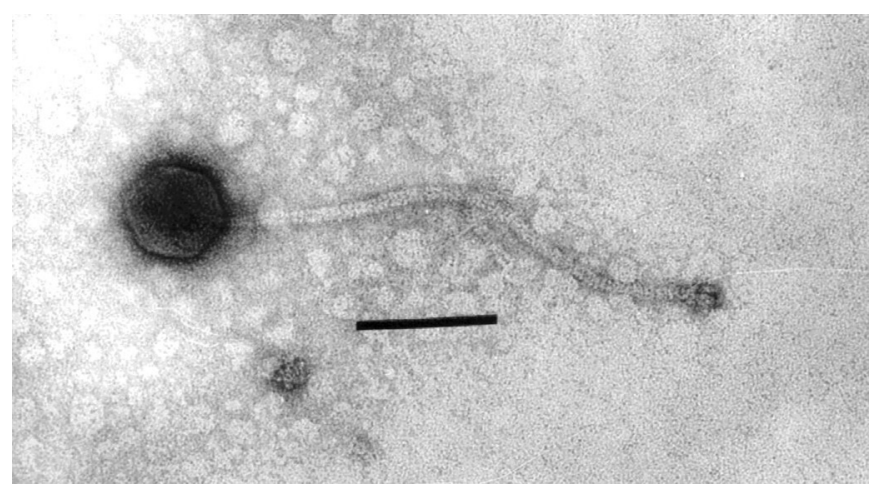

Fig. 1. Transmission electron micrographs of $S$. epidermidis phage vB_SepS_SEP9. The bar indicates $100 \mathrm{~nm}$.

different diameters [32]. It may represent a new species within the Siphoviridae family.

\subsection{Host range and efficiency of plating (EOP)}

A collection of forty-six staphylococcal strains was used to determine SEP9 host range and EOP (Table 1). The $S$. epidermidis strains tested were isolated from diverse types of infection in different countries [13]. SEP9 was specific to S. epidermidis and infected $74 \%$ of the strains tested, which is considerably higher than infection rates of around 38\% observed in other S. epidermidis phages [33]. SEP9 is able to propagate in 14 clinical strains, though with different EOPs (high, moderate and low). Similar to phage SEP1, no correlation was observed between lytic activity and the infection and geographical origin of the strains [13]. Furthermore, in contrast with other staphylococcal Twortlikeviruses [34], SEP9 did not lyse the other staphylococcal species tested.

\subsection{One-step growth curve}

To examine the infection parameters of SEP9, one-step growth curve experiments were performed. SEP9 has a latent period of approximately $10 \mathrm{~min}$ and a burst size of approximately $6.39 \pm 0.47 \mathrm{PFU}$ after $30 \mathrm{~min}$ at $37^{\circ} \mathrm{C}$ (Fig. 2). The short latent period and the small burst size are in accordance with other $S$. epidermidis phages $[33,13]$. The small burst size observed may be related to SEP9's short lysis time [35].

\subsection{Genomic properties}

SEP9 possesses a linear dsDNA genome of 92,417 bp with $\mathrm{a} \mathrm{G}+\mathrm{C}$ content of $29.6 \%$. This $\mathrm{G}+\mathrm{C}$ content is significantly lower than in other S. epidermidis phages $(\sim 32 \%)$ [36] and lower than in 46 other staphylococcal phages $(33-38 \%)$ [9].

This phage displays 129 putative CDSs (coding sequences) that are tightly packed and occupy $\sim 89 \%$ of the genome (Fig. 3). Of these CDSs, 46 have an assigned function and 59 are unique (Table S1). The majority of the CDSs present an

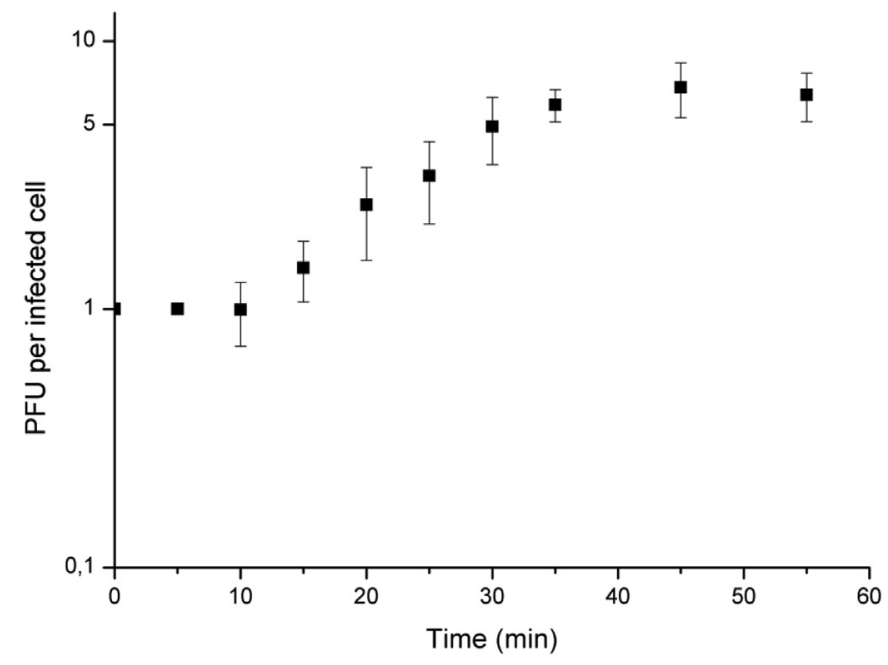

Fig. 2. One-step growth curve of phage vB_SepS_SEP9 in S. epidermidis $\mathrm{M} 129$ at $37^{\circ} \mathrm{C}$. Shown are the PFU per infected cell.

ATG start codon (89\%), while seven start with TTG, five with GTG and two with ATT. A single tRNA gene, specifying a prolyl-tRNA, was discovered in SEP9. A BLASTN search revealed that no identical phages were found in the database. SEP9 genome was compared with its most homologous phage, vB_SepiS-phiIPLA7 and as visible on Fig. 3, there are few homologous regions throughout their genomes. The results showed $79 \%$ of identity with a query of $3 \%$, essentially on the region of tail-associated proteins.

Despite the uniqueness of SEP9, this phage possesses the same modular genomic architecture as the majority of dsDNA phages [37]. Consequently, the packaging, structure/morphogenesis, host lysis and replication/regulation modules are present and well defined throughout the genome. MEME analysis revealed seven putative promoters (consensus: TTGACA(N17)TATAaT) while ARNold/MFOLD revealed eight rho-independent terminators, reinforcing the modular arrangement and suggesting a modular control of gene expression.

The phylogeny of the large subunit terminase (TerL) has been used to predict the packaging strategy used by bacteriophages [38]. SEP9 TerL homologs, identified using BLASTP, are preferentially found in prophage proteins in Bacillus, Kurthia, Lactobacillus, Oribacterium, and Veillonella strains. Restricting the search to "Viruses (taxid: 10239)" resulted in hits among the Bacillus, Enterococcus, Geobacillus, Lactobacillus, Leuconostoc and Staphylococcus phages. A phylogenetic tree constructed using the "one click" mode at phylogeny. fr [39], showed that SEP9 TerL is closely related to TerL proteins of Lactobacillus delbrueckii lytic phages (Fig. S1). Lactobacillus phages c5 and LL-Ku are members of the Siphoviridae and their genomes possess 11-bp $3^{\prime}$ overhang cohesive ends (LL-Ku, 5'-TAACACCCGAA-3'; c5, 5'-AAACACCCGAA-3') [40]. A similar site (CAACACCCGAA) was found between residues 85982 and 85992, 6480 upstream of $t e r L$, which we suspect corresponds to the true left end of the Staphylococcus phage SEP9 genome. The 


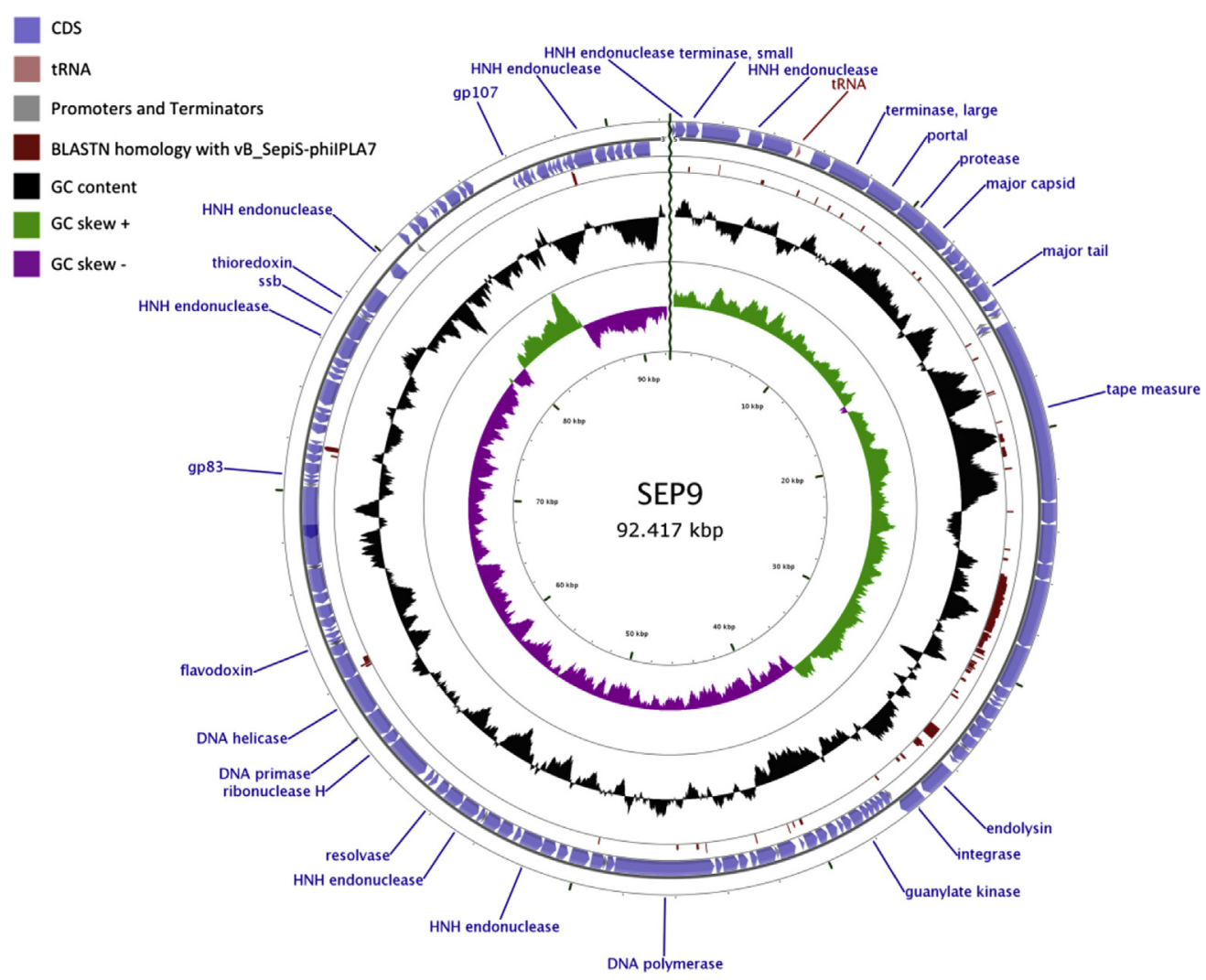

Fig. 3. Circular view of SEP9 genome and BLASTN comparison with vB_SepiS-phiIPLA7. The outer ring represents SEP9 CDSs. At red are represented the homologies with vB_SepiS-phiIPLA7. The GC content appears in the black ring and the green ring is GC skew + and the pink ring is the GC skew-. Some important genes are highlighted. It should be clearly stated when a figure must be published in color. (For interpretation of the references to color in this figure legend, the reader is referred to the web version of this article.)

genome was reopened at this point to render it collinear with that of the Lactobacillus phages. Furthermore, the presence of a prohead protease is an additional argument that favors the hypothesis that SEP9 is a cos-type phage.

In the morphogenesis module, the major capsid protein displays high sequence identity with Lactobacillus phage ATCC 8014-B2, while the major tail protein resembles that of Listeria phage B025. Both phages are also members of the Siphoviridae family. A correlation between the size of the gene encoding the tail-tape measure protein (TMP) and the size of the virion tail has been described [41]. This might explain the very large size of SEP9 tail (375 nm), since the SEP9 gene encoding the TMP is 2395 aa. This protein, like that of other staphylococcal siphoviruses [9] contains an N-terminal lytic transglycosylase SLT domain and a C-terminal peptidase_M23. SEP9 encodes a headtail connector and head-tail adapter are described to be involved in DNA packaging being localized inside the head shell, where the tail attaches [42].

SEP9 also encodes a virion-associated hydrolase with a Nterminal endopeptidase domain (gp16) and a pre-neck appendage protein (gp18) with a pectin-lyase like domain that could be involved in the degradation of extracellular polymers [11]. The presence of depolymerases may help the efficacy of some phages degrading biofilm matrix [11]. In the tail morphogenesis module, two proteins, gp15 and gp19 were predicted to be involved in the receptor binding. Remarkably, these two proteins are homologous to receptor-binding proteins of other CoNS phages [10,5].

SEP9 lysis cassette is comprised of holin and endolysin. Although both proteins are similar to marine Staphylococcus saprophyticus phage $\varphi \mathrm{RS7}$ (NC_022914) lysis proteins, in SEP9 they are separated by two undefined genes (27 and 28). The endolysin contains an N-terminal CHAP endopeptidase domain and a SH3 peptidoglycan-binding domain in the Cterminus separated by an $\mathrm{N}$-acetylmuramoyl-L-alanyl-amidase domain. This structure is typical of Staphylococcus phage endolysins [43]. Furthermore, two transmembrane domains were predicted in the holin, and this protein can be classified as being part of the lactococcal $\varphi \mathrm{LC} 3$ family [44] similar to Staphylococcus phage $\phi 11$ [45].

Although encoding an integrase (gp30), SEP9 does not appear to possess a complete set of genes required for lysogeny. It lacks a repressor of the CI type, which is normally present in other staphylococcal phages [46]. The fact that there are no similar sequences on the more than 80 staphylococcal genomes deposited in databases might suggest that the phage is not temperate. Furthermore, our experiments show that SEP9 is unable to lysogenize, as the 20 selected colonies were sensitive to phage, no phage was detected in their supernatants and the major capsid protein of SEP9 was not detected by PCR on the isolated colonies (data not shown). Results showed that of the 66 putative proteins of SEP9 homologous to other 
phages, 40 are homologous to virulent phages (61\%), while 26 are homologous to temperate phages (39\%), which enlightens the mosaic structure of staphylococcal phages [6].

The replication module differs from that of other staphylococcal phages. SEP9 has a DNA polymerase that is similar to the replicase of Bacillus phage SPBc2. Other replication proteins, namely a repair exonuclease (gp66), DNA primase (gp68) and an exonuclease (gp128) are also similar to that Bacillus phage. SEP9 encodes two DNA methyltransferases (gp58 and gp59) that showed homology to a Campylobacter phage CP220 protein and to Twortlikevirus Staphylococcus phage SA11 respectively. Ribonuclease H (gp67) is a protein that plays a role in mRNA processing. While homologs of this protein are somewhat common in siphoviruses of Proteobacteria, this is the first example in Siphoviridae of Firmicutes. Finally, the ribonucleotide-reductase beta subunit (gp78) is homologous to that of Listeria phage A511 (Myoviridae) and the ribonucleotide-reductase alpha subunit (gp81) is homologous to those of Bacillus siphoviruses Slash and Staley.

Interestingly, a response regulator (gp98) was predicted after the detection of a HTH_LUXR domain, which is part of transcriptional regulators of LuxR family [47]. Regulators with this motif have been reported previously in other virulent phages genomes [48], however, using BLASTP no homologies were detected between gp98 and other phage proteins.

Overall, seven ORFs coding for HNH endonucleases and two intron-associated endonucleases were annotated in SEP9 genome. These proteins are commonly observed in phages of the genus Twortlikevirus [34], but are rare in staphylococcal Siphoviridae phages. Nevertheless, they were observed in phages 85 and X2 [49], and are stated to be involved in insertion or transposon elements on phage genomes [50]. Furthermore, using both BLASTP and HHPred no virulence genes, of bacterial origin, were detected, which is important to select good candidates for phage therapy [51].

\subsection{Concluding remarks}

A novel virulent $S$. epidermidis phage SEP9 was characterized. This phage has a broad lytic spectrum and a short life cycle. Its morphology is different from those of the already defined genera "77likevirus", "3alikevirus" and "Phietalikevirus" of staphylococcal siphoviruses. Its linear dsDNA genome has 129 CDSs, including 59 unique CDSs, and no identified virulence genes. Morphological and genomic unique characteristics of this phage led to the proposal of the creation of a new Siphoviridae genus named "Sep9likevirus".

\section{Conflict of interest}

There is no conflict of interest.

\section{Acknowledgments}

L. D. R. M., S. S., J. A. and N. C. thank the FCT Strategic Project PEst-OE/EQB/LA0023/2013 and the Project "BioHealth - Biotechnology and Bioengineering approaches to improve health quality", Ref. NORTE-07-0124-FEDER000027, co-funded by the Programa Operacional Regional do Norte (ON.2 - O Novo Norte), QREN, FEDER. The authors also acknowledge the project "Consolidating Research Expertise and Resources on Cellular and Molecular Biotechnology at CEB/IBB”, Ref. FCOMP-01-0124-FEDER-027462. L. D. R. M. and S. S. acknowledge Fundação para a Ciência e a Tecnologia grants SFRH/BD/66166/2009 and SFRH/BPD/ $48803 / 2008$, respectively. NC is an Investigador FCT.

\section{Appendix A. Supplementary data}

Supplementary data related to this article can be found at http://dx.doi.org/10.1016/j.resmic.2014.09.012.

\section{References}

[1] Otto M. Staphylococcus epidermidis-the 'accidental' pathogen. Nat Rev Microbiol 2009;7:555-67.

[2] Otto M. Basis of virulence in community-associated methicillin-resistant Staphylococcus aureus. Annu Rev Microbiol 2010;64:143-62.

[3] Sulakvelidze A, Morris Jr JG. Bacteriophages as therapeutic agents. Ann Med 2001;33:507-9.

[4] King AMQ, Adams MJ, Carstens EB, Lefkowitz EJ. Virus taxonomy: ninth report of the international committee on taxonomy of viruses. Elsevier; 2011.

[5] Deghorain M, Bobay LM, Smeesters PR, Bousbata S, Vermeersch M, Perez-Morga D, et al. Characterization of novel phages isolated in coagulase-negative staphylococci reveals evolutionary relationships with Staphylococcus aureus phages. J Bacteriol 2012;194:5829-39.

[6] Deghorain M, Van Melderen L. The staphylococci phages family: an overview. Viruses 2012;4:3316-35.

[7] Lavigne R, Darius P, Summer EJ, Seto D, Mahadevan P, Nilsson AS, et al. Classification of Myoviridae bacteriophages using protein sequence similarity. BMC Microbiol 2009;9:224.

[8] Lavigne R, Seto D, Mahadevan P, Ackermann H-W, Kropinski AM. Unifying classical and molecular taxonomic classification: analysis of the Podoviridae using BLASTP-based tools. Res Microbiol 2008;159:406-14.

[9] Gutierrez D, Adriaenssens EM, Martinez B, Rodriguez A, Lavigne R, Kropinski AM, et al. Three proposed new bacteriophage genera of staphylococcal phages: "3alikevirus", "77likevirus" and "Phietalikevirus". Arch Virol 2013;159(2):389-98.

[10] Daniel A, Bonnen PE, Fischetti VA. First complete genome sequence of two Staphylococcus epidermidis bacteriophages. J Bacteriol 2007;189:2086-100.

[11] Gutierrez D, Martinez B, Rodriguez A, Garcia P. Genomic characterization of two Staphylococcus epidermidis bacteriophages with antibiofilm potential. BMC Genomics 2012;13:228.

[12] Madhusoodanan J, Seo KS, Remortel B, Park JY, Hwang SY, Fox LK, et al. An enterotoxin-bearing pathogenicity island in Staphylococcus epidermidis. J Bacteriol 2011;193:1854-62.

[13] Melo LD, Sillankorva S, Ackermann H-W, Kropinski AM, Azeredo J, Cerca N. Isolation and characterization of a new Staphylococcus epidermidis broad-spectrum bacteriophage. J Gen Virol 2014;95:506-15.

[14] Luzzaro F, Ortisi G, Larosa M, Drago M, Brigante G, Gesu G. Prevalence and epidemiology of microbial pathogens causing bloodstream infections: results of the OASIS multicenter study. Diagn Microbiol Infect Dis 2011;69:363-9.

[15] Sillankorva S, Neubauer P, Azeredo J. Phage control of dual species biofilms of Pseudomonas fluorescens and Staphylococcus lentus. Biofouling 2010;26:567-75. 
[16] Ackermann H-W. Basic phage electron microscopy. Methods Mol Biol 2009;501:113-26.

[17] Cavalli-Sforza LL, Lederberg J. Isolation of pre-adaptive mutants in bacteria by sib selection. Genetics 1956;41:367-81.

[18] Aziz RK, Bartels D, Best AA, DeJongh M, Disz T, Edwards RA, et al. The RAST server: rapid annotations using subsystems technology. BMC genomics 2008;9:75.

[19] Altschul SF, Madden TL, Schaffer AA, Zhang J, Zhang Z, Miller W, et al. Gapped BLAST and PSI-BLAST: a new generation of protein database search programs. Nucleic Acids Res 1997;25:3389-402.

[20] Altschul SF, Gish W, Miller W, Myers EW, Lipman DJ. Basic local alignment search tool. J Mol Biol 1990;215:403-10.

[21] Soding J, Biegert A, Lupas AN. The HHpred interactive server for protein homology detection and structure prediction. Nucleic Acids Res 2005;33:W244-8.

[22] Kall L, Sonnhammer EL. Reliability of transmembrane predictions in whole-genome data. FEBS Lett 2002;532:415-8.

[23] Kall L, Krogh A, Sonnhammer EL. A combined transmembrane topology and signal peptide prediction method. J Mol Biol 2004;338:1027-36.

[24] Wilkins MR, Gasteiger E, Bairoch A, Sanchez JC, Williams KL, Appel RD, et al. Protein identification and analysis tools in the ExPASy server. Methods Mol Biol 1999;112:531-52.

[25] Laslett D, Canback B. ARAGORN, a program to detect tRNA genes and tmRNA genes in nucleotide sequences. Nucleic Acids Res 2004;32:11-6.

[26] Schattner P, Brooks AN, Lowe TM. The tRNAscan-SE, snoscan and snoGPS web servers for the detection of tRNAs and snoRNAs. Nucleic Acids Res 2005;33:W686-9.

[27] Bailey TL, Boden M, Buske FA, Frith M, Grant CE, Clementi L, et al. MEME SUITE: tools for motif discovery and searching. Nucleic Acids Res 2009;37:W202-8.

[28] Naville M, Ghuillot-Gaudeffroy A, Marchais A, Gautheret D. ARNold: a web tool for the prediction of rho-independent transcription terminators. RNA Biol 2011;8:11-3.

[29] Zuker M. Mfold web server for nucleic acid folding and hybridization prediction. Nucleic Acids Res 2003;31:3406-15.

[30] Hughes KA, Sutherland IW, Jones MV. Biofilm susceptibility to bacteriophage attack: the role of phage-borne polysaccharide depolymerase. Microbiology 1998;144(Pt 11):3039-47.

[31] Kropinski AM, Prangishvili D, Lavigne R. Position paper: the creation of a rational scheme for the nomenclature of viruses of bacteria and archaea. Environ Microbiol 2009;11:2775-7.

[32] Walker Jr DH, Anderson TF. Morphological variants of coliphage P1. J Virol 1970;5:765-82.

[33] Gutierrez D, Martinez B, Rodriguez A, Garcia P. Isolation and characterization of bacteriophages infecting Staphylococcus epidermidis. Curr Microbiol 2010;61:601-8.

[34] Lobocka M, Hejnowicz MS, Dabrowski K, Gozdek A, Kosakowski J, Witkowska M, et al. Genomics of staphylococcal twort-like phages-potential therapeutics of the post-antibiotic era. Adv Virus Res 2012;83:143-216.

[35] Wang IN. Lysis timing and bacteriophage fitness. Genetics 2006; 172:17-26.

[36] Benson DA, Karsch-Mizrachi I, Lipman DJ, Ostell J, Sayers EW. GenBank. Nucleic Acids Res 2009;37:D26-31.

[37] Hatfull GF. Bacteriophage genomics. Curr Opin Microbiol 2008; 11:447-53.

[38] Casjens SR, Gilcrease EB. Determining DNA packaging strategy by analysis of the termini of the chromosomes in tailed-bacteriophage virions. Methods Mol Biol 2009;502:91-111.

[39] Dereeper A, Guignon V, Blanc G, Audic S, Buffet S, Chevenet F, et al. Phylogeny.fr: robust phylogenetic analysis for the non-specialist. Nucleic Acids Res 2008;36:W465-9.

[40] Riipinen KA, Forsman P, Alatossava T. The genomes and comparative genomics of Lactobacillus delbrueckii phages. Arch Virol 2011;156:1217-33.

[41] Katsura I, Hendrix RW. Length determination in bacteriophage lambda tails. Cell 1984;39:691-8.

[42] Tavares P, Zinn-Justin S, Orlova EV. Genome gating in tailed bacteriophage capsids. Adv Exp Med Biol 2012;726:585-600.

[43] Oliveira H, Melo LD, Santos SB, Nobrega FL, Ferreira EC, Cerca N, et al. Molecular aspects and comparative genomics of bacteriophage endolysins. J Virol 2013;87:4558-70.

[44] Birkeland NK. Cloning, molecular characterization, and expression of the genes encoding the lytic functions of lactococcal bacteriophage phi LC3: a dual lysis system of modular design. Can J Microbiol 1994;40:658-65.

[45] Donovan DM, Foster-Frey J, Garrett WM, Blomberg L. Resolving the database sequence discrepancies for the Staphylococcus aureus bacteriophage $\phi 11$ amidase. J Basic Microbiol 2008;48:48-52.

[46] Garcia P, Martinez B, Obeso JM, Lavigne R, Lurz R, Rodriguez A. Functional genomic analysis of two Staphylococcus aureus phages isolated from the dairy environment. Appl Environ Microbiol 2009;75:7663-73.

[47] Hargreaves KR, Kropinski AM, Clokie MR. What does the talking?: quorum sensing signalling genes discovered in a bacteriophage genome. PLoS One 2014;9:e85131.

[48] Mayer MJ, Payne J, Gasson MJ, Narbad A. Genomic sequence and characterization of the virulent bacteriophage phiCTP1 from Clostridium tyrobutyricum and heterologous expression of its endolysin. Appl Environ Microbiol 2010;76:5415-22.

[49] Kwan T, Liu J, DuBow M, Gros P, Pelletier J. The complete genomes and proteomes of 27 Staphylococcus aureus bacteriophages. Proc Natl Acad Sci U S A 2005;102:5174-9.

[50] Ceyssens PJ, Hertveldt K, Ackermann HW, Noben JP, Demeke M, Volckaert G, et al. The intron-containing genome of the lytic Pseudomonas phage LUZ24 resembles the temperate phage PaP3. Virology 2008;377:233-8.

[51] Loc-Carrillo C, Abedon ST. Pros and cons of phage therapy. Bacteriophage 2011;1:111-4. 